ПСОРИАЗ И МЕТАБОЛИЧЕСКИЙ СИНДРОМ: ОБЗОР ЛИТЕРАТУРЫ

( М.А. Уфимцева, А.А. Попов, Л.В. Федотова, Е.С. Мыльникова*, Ю.М. Бочкарев, Д.С. Жунисова

Уральский государственный медицинский университет, Екатеринбург, Россия

Псориаз является самым распространенным хроническим дерматозом и встречается у 1-2\% населения развитых стран. В Российской Федерации отмечается прирост заболеваемости на 11\% за период с 2011 по 2018 гг. Псориаз хроническое иммуновоспалительное заболевание кожи - часто ассоциируется с полным метаболическим синдромом или его компонентами: ожирением, артериальной гипертензией, инсулинорезистентностью, дислипидемией. Риск развития метаболического синдрома у пациентов с псориазом на 40\% выше, чем в общей популяции. Общими звеньями патогенеза псориаза и метаболического синдрома являются хроническое системное вялотекущее воспаление и повышение уровня провоспалительных цитокинов. Системное воспаление способствует развитию ожирения, заболеваний сердечно-сосудистой системы, сахарного диабета 2 типа. Эти состояния приводят к повышению смертности среди пациентов с псориазом. Существует положительная связь между тяжестью течения псориаза и наличием метаболического синдрома, что проявляется большей распространенностью высыпаний, сокращением сроков ремиссии и повышенным риском развития псориатического артрита. У носителей аллелей риска ожирения гена FTO наблюдается более тяжелое течение псориаза, наличие псориатического артрита, повышение индекса массы тела. В статье представлен обзор литературы, посвященный вопросам эпидемиологии, этиологии, патогенеза псориаза и метаболического синдрома.

КЛЮЧЕВЫЕ СЛОВА: псориаз; метаболический синдром; ожирение; коморбидность; полиморфизм генов; FTO.

\title{
PSORIASIS AND METABOLIC SYNDROME: A REVIEW
}

(c) Marina A. Ufimtseva, Artem A. Popov, Larisa V. Fedotova, Ekaterina S. Mylnikova*, Yuri M. Bochkarev, Dinara S. Zhunisova

Urals State Medical University, Yekaterinburg, Russia

Psoriasis is the most common chronic dermatosis and affects $1-2 \%$ of the population of developed countries. In Russia, psoriasis incidence rate has increased by $11 \%$ since 2011 . Psoriasis is a chronic inflammatory and immune-mediated skin disease and it is often associated with metabolic syndrome and its components such as obesity, arterial hypertension, insulin resistance and dyslipidemia. The risk of developing metabolic syndrome in patients with psoriasis is $40 \%$ higher than in the general population. Psoriasis and metabolic syndrome share some pathogenic mechanisms such as chronic low-grade systemic inflammation and an increased level of pro-inflammatory cytokines. Systemic inflammation causes obesity, cardiovascular diseases, diabetes. These conditions increase the risk of mortality among patients. There is a link between the severity of psoriasis and metabolic syndrome and associated with severe rash, reduction of the remission and higher risk of psoriatic arthritis development. The carriers of the risk allele of FTO gene are associated with severe psoriasis, presence of psoriatic arthritis and obesity. The article presents the issues of epidemiology, etiology and pathogenesis of psoriasis and metabolic syndrome.

KEYWORDS: psoriasis; metabolic syndrome; obesity; comorbidity; genetic polymorphism; alpha-ketoglutarate-dependent dioxygenase FTO.

\section{ВВЕДЕНИЕ}

Псориаз является одним из наиболее распространенных хронических дерматозов и среди населения развитых стран встречается в 1-2\% случаев. В 2018 г. распространенность псориаза в Российской Федерации (РФ) составила 242,4, заболеваемость - 66,5 на 100 тысяч населения. Отмечается прирост распространенности псориаза в популяции на $11 \%$ за период 2011-2018 гг. [1].

Псориаз - хроническое иммуновоспалительное заболевание кожи - нередко сочетается как с полным метаболическим синдромом (МС), так и отдельными его компонентами: заболеваниями сердечно-сосудистой системы, сахарным диабетом (СД) 2 типа, ожирением, неалкогольной жировой болезнью печени [2].

МС характеризуется увеличением массы висцерального жира, снижением чувствительности периферических тканей к инсулину и гиперинсулинемией, которые вызывают нарушения углеводного, липидного, пуринового обменов и артериальную гипертензию. Критерии постановки диагноза МС представлены в табл. 1. МС выявляется у 25\% населения [5]. В России распространенность ожирения и избыточной массы тела в общей популяции составляет от 20,5 до 54\% [6]. А среди пациентов с ожирением у 72\% выявляется абдоминальное ожирение, у 40\% - артериальная гипертензия, у 30\% - дислипидемия, у 12\% - нарушение толерантности к глюкозе [7]. 
Таблица 1. Критерии диагностики метаболического синдрома IDF (2005) и NCEP ATP III (2001)

\begin{tabular}{|c|c|}
\hline Критерии IDF (2005) [3] & Критерии NCEP ATP III (2001) [4] \\
\hline $\begin{array}{l}\text { Центральное (абдоминальное) ожирение } \\
\text { (ОТ более } 80 \text { см у женщин и более } 94 \text { см у мужчин). } \\
\text { Любые два пункта из нижеперечисленных: } \\
\text { 1. Повышение уровня триглицеридов } \geq 1,7 \text { ммоль/л } \\
\text { 2. Низкая концентрация лПВП (мужчины <1,03 ммоль/л, }\end{array}$ & $\begin{array}{l}\text { Любые три пункта из нижеперечисленных. } \\
\text { 1. ОТ у мужчин } \geq 102 \text { см, у женщин } \geq 88 \text { см. } \\
\text { 2. Повышение уровня триглицеридов выше } \geq 1,7 \text { ммоль/л. } \\
\text { 3. Низкая концентрация ЛПВП (мужчины <1,03 ммоль/л, } \\
\text { женщины <1,29 ммоль/л). }\end{array}$ \\
\hline
\end{tabular}

4. Повышение АД: систолическое АД $\geq 130$ мм рт.ст.

3. Повышение АД: систолическое АД $\geq 130$ мм рт.ст. или диастолическое АД $\geq 85$ мм рт. ст. или лечение прежде диагностированной АГ.

4. Повышение уровня глюкозы натощак выше 25,6 ммоль/л или ранее диагностированный СД. или диастолическое АД $\geq 85$ мм рт. ст. или лечение ранее диагностированной АГ.

5. Повышение уровня глюкозы натощак выше 26,1 ммоль/л или прежде диагностированный СД.

Примечание. IDF — International Diabetes Federation; NCEP ATP III — National Cholesterol Education Program Adult Treatment Panel III; OT — окружность талии; ЛПВП - липопротеиды высокой плотности; АД - артериальное давление; СД - сахарный диабет; АГ - артериальная гипертензия.

Многочисленные исследования указывают на взаимосвязь псориаза и МС [8-10]. Риск развития МС у пациентов с псориазом выше на 40\%, чем в общей популяции [5]. Псориаз и МС имеют общие звенья патогенеза, а именно хроническое вялотекущее системное воспаление и повышенный уровень провоспалительных цитокинов: интерферон-гамма, интерлейкинов (IL) IL-17, IL-23, фактора некроза опухоли альфа (ФНО-а). Воспаление индуцирует инсулинорезистентность, эндотелиальную дисфункцию и, как следствие, развитие сердечно-сосудистых заболеваний. Системное воспаление также провоцирует развитие ожирения, артериальной гипертензии (АГ), дислипидемии и СД 2 типа, являющихся причиной повышенной смертности пациентов с псориазом $[5,8,11]$.

В настоящем обзоре рассмотрены вопросы коморбидности псориаза и МС, влияния полиморфизмов гена FTO на развитие ожирения и течение дерматоза. Исследование проводилось с помощью поисково-информационных баз данных PubMed, eLibrary методом анализа и интерпретации. Поиск научных публикаций проводился по ключевым словам: «метаболический синдром; псориаз; ожирение; ген FTO; metabolic syndrome; psoriasis; obesity; FTO gene» за последние 10 лет. Всего найдено 3057 работ, после удаления дублирующих публикаций и работ, не соответствующих целям исследования, было получено 52 ссылки.

\section{ОСОБЕННОСТИ ТЕЧЕНИЯ ПСОРИАЗА ПРИ СОПУТСТВУЮЩЕМ МЕТАБОЛИЧЕСКОМ СИНДРОМЕ}

Описана положительная связь между МС и тяжестью течения псориаза, проявляющаяся большей распространенностью высыпаний, сокращением сроков ремиссии. Обострения нередко сопровождаются более выраженной воспалительной реакцией: резкой гиперемией, инфильтрацией, обильным шелушением, вплоть до образования чешуе-корок [12]. При нерациональном выборе наружной терапии и нарушении техники применения существует вероятность присоединения бактериальной инфекции и возникновения пиодермических элементов. Кроме того, у пациентов с псориазом и нарушением углеводного обмена часто встречается кандидозная инфекция в области складок кожи вследствие нарушенного потоотделения, мацерации и повышенного трения [12]. Нерациональная наружная терапия в этом случае приводит к распространению грибковой инфекции, появлению обширных очагов, выраженной инфильтрации, яркой гиперемии. Коморбидность псориаза и МС характеризуется повышенным риском развития псориатического артрита, сердечно-сосудистых заболеваний $[13,14]$. Кроме того, психоэмоциональные нарушения в виде повышения уровня личностной и ситуативной тревожности, также депрессивные состояния встречаются у больных псориазом, сочетанным с МС, значимо чаще, чем у больных дерматозом без признаков МС [15].

У пациентов с псориазом и МС показатели уровня Среактивного белка, общей окислительной активности значимо выше, чем у пациентов с псориазом без признаков МС. В то же время значения общей антиоксидантной защиты и одного из важнейших компонентов антиоксидантной защиты - супероксиддисмутазы - оказались существенно ниже, чем у пациентов с псориазом без МС [16-19].

При легком течении дерматоза нормальный показатель индекса массы тела (ИМТ) был установлен у 63,8\% мужчин и 71,4\% женщин. Нормальные значения массо-ростовых показателей при псориазе средней степени тяжести имели лишь 42,9\% мужчин и 34,8\% женщин. При тяжелом течении ИМТ, соответствующий норме, был выявлен только у 14,2\% мужчин [20]. Анализ пищевого поведения, пищевого статуса, составляющих образа жизни, таких как фактическое питание, наличие вредных привычек, у 261 больного вульгарным псориазом в возрасте от 18 до 59 лет показал, что пациенты с легким течением дерматоза в целом ведут более правильный образ жизни по сравнению с имеющими среднетяжелую форму [21]. В группе пациентов со среднетяжелым псориазом средний уровень содержания жира в композиционном составе тела был достоверно выше, чем у пациентов с легким течением псориаза. Изменения биохимических показателей, отражающих нарушения белкового, углеводного и липидного обменов при среднетяжелом течении дерматоза встречались значимо чаще [22].

Пациенты с избыточной массой тела и ожирением подвержены риску более тяжелого и часто рецидивирующего течения псориаза. При исследовании 124 больных

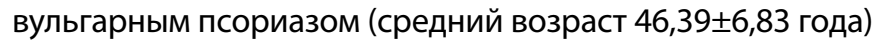


дис- и/или гиперлипопротеинемия наблюдались у большинства больных (85,1\%), а липидная триада обнаружена у 20,2\%. При анализе результатов глюкозотолерантного теста у 85,1\% пациентов были выявлены различные варианты нарушения углеводного обмена. Также у пациентов обнаружена выраженная инсулинорезистентность, которая характеризовалась повышением концентрации базального уровня инсулина и индекса HOMA-IR в среднем в 2 раза. У лиц, страдающих вульгарным псориазом, была обнаружена гиперлептинемия, при этом повышение показателей лептина было выявлено как у лиц с нормальным ИМТ, так и с ИМТ>25. При исследовании пищевого поведения у больных с ИМТ> 25 были выявлены следующие соотношения: эмоциогенное пищевое поведение - у 20,2\% пациентов, экстернальное пищевое поведение - у 43,6\% лиц, ограничительное пищевое поведение - у 36,2\%. Аналогичные нарушения были обнаружены у пациентов с нормальной массой тела: эмоциогенное пищевое поведение - 20\%, экстернальное пищевое поведение $36,7 \%$, ограничительное пищевое поведение - 43,3\%. Эти данные указывают на первичную гормонально-метаболическую составляющую повышения массы тела у больных вульгарным псориазом [23].

MC является независимым фактором риска тяжелого течения дерматоза. Учитывая ряд схожих патогенетических механизмов, роль хронического системного воспаления в развитии коморбидности МС и псориаза становится все более признанной. При этом важно отметить, что на тяжесть течения псориаза во многом влияет образ жизни пациента. Вредные привычки, расстройства пищевого поведения и психоэмоциональные нарушения приводят к дальнейшему увеличению избыточной массы тела и, как следствие, более тяжелому течению дерматоза. Таким образом, тактика ведения больных псориазом с сопутствующим MC подразумевает не только углубленный скрининг на выявление метаболических нарушений, но и активное взаимодействие врачей различных специальностей.

\section{ГЕН FТО В РАЗВИТИИ ОЖИРЕНИЯ И МС}

Ожирение является заболеванием с мультифакториальным генезом. Значительный вклад в повышение распространенности ожирения вносит изменившийся образ жизни и питания; значимыми предикторами развития заболевания являются и генетические факторы [24]. Исследование, направленное на полногеномный поиск ассоциаций (genome-wide association studies, GWAS), выявило более 50 генов, особое внимание из которых вызывает ген, ассоциированный с жировой массой и ожирением (fat mass and obesity associated gene, FTO) [25]. В исследовании GWAS носители аллелей риска ожирения гена FTO сравнительно чаще страдали ожирением и метаболическими нарушениями [26]. Предполагается, что около половины населения мира являются носителями аллеля риска ожирения гена FTO, однако данных о частоте встречаемости полиморфизмов в российской популяции больных псориазом обнаружить не удалось [27].

Ген FTO находится на длинном плече 16 хромосомы в позиции 12.2 и состоит из 9 экзонов. Все полиморфизмы гена FTO, изучаемые на настоящий момент, локализованы в первом интроне гена [28]. Ген FTO кодирует 2-оксоглутарат-зависимую деметилазу нуклеиновых кислот - белок, который участвует в восстановлении ДНК, регуляции энергетического обмена и липолизе $[26,29]$. Ген FTO экспрессируется во многих тканях, относительно высокий уровень экспрессии гена обнаружен в клетках головного мозга, в частности гипоталамуса [30]. Ген FTO регулирует экспрессию двух других генов: IRX3 (iroquois homeobox 3) и IRX5 (iroquois homeobox 5). Эти гены обусловливают дифференцировку белой и бурой жировой ткани у плода. Низкий уровень экспрессии генов стимулирует развитие бурой жировой ткани в большей степени, чем белой. Соответственно, высокий уровень экспрессии связан с образованием белой жировой ткани [31].

Показано, что однонуклеотидные полиморфизмы rs9930609 и rs9930506 (аллель риска ожирения A и G coответственно) положительно коррелируют с риском развития ожирения и МС [32-34]. Среди всех изученных полиморфизмов гена FTO rs9939609 влияет на развитие ожирения наиболее выраженно особенно в европейской популяции, где частота встречаемости аллеля риска ожирения А близка к 60\%, а генотип АА ассоциирован с увеличением массы тела в среднем на 3 кг, чем в популяции [28]. Считается, что полиморфный маркер rs9939609 гена FTO сцеплен с полиморфным маркером rs1424233 гена MAF (musculoaponeurotic fibrosarcoma oncogene homolog), который также ассоциирован с ожирением и повышением массы тела [35-38]. Оба гена локализованы в 16 хромосоме, ген MAF находится в позиции 16q22-23 [39]. Точные механизмы влияния генетического полиморфизма rs9930609 гена FTO неясны. J.R. Speakman и соавт. (2008) предположили, что он влияет на особенности пищевого поведения, а не на расход энергии [40]. По данным G. Castellini и соавт. (2017), существует статистически значимая связь между наличием аллеля А полиморфизма rs9939609 и развитием расстройств пищевого поведения, что выражалось в переедании, характерном для нервной анорексии и нервной булимии. Кроме того, у пациентов с расстройством пищевого поведения и наличием аллеля А полиморфизма rs9939609 наблюдались выраженные психопатологические клинические особенности поведения, такие как эмоциональное переедание и дисморфофобия [41].

У носителей генотипа AA гена FTO отмечается ослабленное подавление чувства голода вследствие повышения концентрации грелина, который вызывает усиление аппетита, в сравнении с носителями генотипа ТТ. С помощью функциональной МРТ Е. Karra и соавт. (2013) продемонстрировали, что носители аллеля А в генотипе модулируют нейронные ответы на изображения еды в структурах системы вознаграждения в головном мозге. У носителей генотипа АА и ТТ обнаружена различная чувствительность к циркулирующему ацилированному грелину в областях головного мозга, которые регулируют аппетит, обработку сигналов вознаграждения и мотивацию. Эти результаты могут объяснять предрасположенность к развитию ожирения посредством регуляции сигналов системы вознаграждения и пищевого центра [42]. Можно предположить, что носители генотипа АA предрасположены к большему потреблению калорий, следовательно, к большей жировой массе [43].

В исследовании 205 условно здоровых мужчин частота встречаемости аллеля риска ожирения А гена FTO составила 60\% [44]. Носители аллеля А гена FTO в условиях отсутствия регулярной физической нагрузки 
и ограничений в диете склонны к абдоминальному жироотложению с преимущественным накоплением висцерального жира [42].

Таким образом, основываясь на результатах вышеизложенных исследований, следует учитывать, что полиморфизмы гена FTO во многом влияют на пищевое поведение, приводя к перееданию и увеличению избыточной массы тела. Однако при соблюдении диеты и наличии регулярных физических нагрузок эффект генетических полиморфизмов в значительной степени нивелируется, что позволяет профилактировать ожирение.

Уровень липопротеинов высокой плотности (ЛПВП) у гомозигот по аллелю риска ожирения А оказался значимо ниже, чем у гомозигот по аллелю ТТ [30, 45]. Выявлена положительная корреляция между уровнем лептина и наличием полиморфизма гена FTO, которая, однако, исчезает после поправки на количество потребляемых калорий и физическую активность [30, 46, 47]. В других выборках, с включением детей и подростков, не было найдено связи между наличием аллеля риска ожирения гена FTO в генотипе и уровнями ЛПВП и лептина, что дает основания для предположения, что связь полиморфизма гена FTO с уровнями ЛПВП и лептина может меняться в ходе онтогенеза [48, 49].

Обнаружена ассоциация полиморфизмов гена FTO с другими компонентами МC. Наличие аллеля риска ожирения гена FTO увеличивает риск развития СД на 15\% [26]. Во французской популяции носители аллеля риска ожирения А гена FTO имели на 48\% более высокий риск развития СД 2 типа [32]. Аналогичная связь описана между наличием полиморфизма rs9939609 и развитием АГ [50].

\section{ВЛИЯНИЕ ПОЛИМОРФИЗМОВ ГЕНА FТО НА ТЕЧЕНИЕ ПСОРИАЗА}

Гомозиготные по аллели G гена FTO rs9930506 пациенты с псориазом имели значимо более высокий ИМТ, риск развития ожирения и, вероятно, псориатического артрита [51]. Среднее значение индекса PASI у носителей генотипа AA было выше, чем у носителей генотипа ТТ [52]. В разных популяциях носители хотя бы одного аллеля риска ожирения (А) имели значимо более высокий уровень С-реактивного белка, что отражает и генетическую предрасположенность к более выраженному воспалительному ответу при сочетании псориаза и МС [51, 52]. Эти результаты свидетельствуют о том, что полиморфизмы гена FTO способствуют более тяжелому течению дерматоза, а также риску развития метаболических нарушений у пациентов. Можно предпо- ложить, что генетические исследования полиморфизмов гена FTO позволят прогнозировать развитие MC у больных псориазом и оптимизировать выбор тактики ведения таких пациентов. Однако вследствие отсутствия данных о частоте встречаемости и клинической значимости обсуждаемых полиморфизмов в российской популяции требуется дальнейшее изучение данной проблемы.

\section{ЗАКЛЮЧЕНИЕ}

Псориаз - это хроническое иммуновоспалительное заболевание, которое часто ассоциировано с МС и другими коморбидными состояниями. МС встречается на $40 \%$ чаще у пациентов с псориазом и способствует не только более тяжелому течению дерматоза, но и повышению сердечно-сосудистой смертности. У пациентов с псориазом и сопутствующим MC чаще наблюдаются повышение уровня С-реактивного белка, провоспалительных цитокинов. У носителей хотя бы одного аллеля риска ожирения гена FTO псориаз протекает тяжелее, повышается риск развития псориатического артрита, проявления системного воспаления более выражены.

Приведенные данные подтверждают высокую актуальность изучения подходов к персонифицированному лечению псориаза и сопутствующего МС и обосновывает необходимость тесного взаимодействия врачей различных специальностей.

\section{ДОПОЛНИТЕЛЬНАЯ ИНФОРМАЦИЯ}

Источники финансирования. Работа выполнена по инициативе авторов без привлечения финансирования.

Конфликт интересов. Авторы декларируют отсутствие явных и потенциальных конфликтов интересов, связанных с содержанием настоящей статьи.

Участие авторов. Уфимцева М.А. - концепция статьи, анализ публикаций, интерпретация результатов, внесение существенных правок с целью повышения научной ценности статьи; Попов А.А. - анализ публикаций, интерпретация результатов, внесение существенных правок с целью повышения научной ценности статьи; Федотова Л.В. - анализ публикаций, внесение существенных правок с целью повышения научной ценности статьи; Мыльникова Е.С. - сбор и систематизация данных, написание статьи; Бочкарев Ю.М. - анализ публикаций, внесение существенных правок с целью повышения научной ценности статьи; Жунисова Д.С. - сбор и систематизация данных, написание статьи. Все авторы одобрили финальную версию статьи перед публикацией, выразили согласие нести ответственность за все аспекты работы, подразумевающую надлежащее изучение и решение вопросов, связанных с точностью или добросовестностью любой части работы.

\section{СПИСОК ЛИТЕРАТУРЫ | REFERENCES}

1. Кубанов А.А., Богданова Е.В. Организация и результаты оказания медицинской помощи по профилю «дерматовенерология» в Российской Федерации. Итоги 2018 года // Вестник дерматологии и венерологии. - 2019. - Т. 95. — №4. - С. 8-13. [Kubanov AA, Bogdanova EV. Dermatovenereologic health care delivery management in the Russian Federation. Results of 2018 Vestnik dermatologii i venerologii. 2019;95(4):8-13. (In Russ.)] doi: https://doi.org/10.25208/0042-4609-2019-95-4-8-23

2. Gisondi P, Fostini AC, Fossà l, et al. Psoriasis and the Metabolic Syndrome. Clin Dermatol. 2018;36(1):21-28. doi: https://doi.org/10.1016/j.clindermatol.2017.09.005
3. IDF.org [Internet]. The IDF worldwide definition of the metabolic syndrome [cited: 2020, Jun 02]. Available from: https://www.idf. org/e-library/consensus-statements/60-idfconsensus-worldwidedefinitionof-the-metabolic-syndrome.html

4. Expert Panel on Detection, Evaluation and $T$ of $\mathrm{HBC}$ in A. Executive Summary of the Third Report of the National Cholesterol Education Program (NCEP) Expert Panel on Detection, Evaluation, and Treatment of High Blood Cholesterol in Adults (Adult Treatment Panel III). JAMA J Am Med Assoc. 2001;285(19):2486-2497. doi: https://doi.org/10.1001/jama.285.19.2486 
5. Rodríguez-Zúñiga MJM, García-Perdomo HA. Systematic Review and Meta-Analysis of the Association Between Psoriasis and Metabolic Syndrome. J Am Acad Dermatol. 2017;77(4):657-666. doi: https://doi.org/10.1016/j.jaad.2017.04.1133

6. Лескова И.В., Ершова Е.В., Никитина Е.А., и др. Ожирение в России: современный взгляд под углом социальных проблем // Ожирение и метаболизм. - 2019. - Т. 16. №1. - C. 20-26. [Leskova IV, Ershova EV, Nikitina EA, et al. Obesity in Russia: modern view in the light of a social problems. Obesity and metabolism. 2019;16(1):20-26. (In Russ.)]. doi: https://doi.org/10.14341/omet9988

7. Кочетова О.В., Ахмадишина Л.З., Корытина Г.Ф., и др. Анализ роли полиморфных вариантов генов, ассоциированных с ожирением, в развитии метаболического синдрома у женщин // Ожирение и метаболизм. - 2017. - Т. 14. - №2. - C. 33-40. [Kochetova OV, Akhmadishina LZ, Korytina GF, et al. Association of obesity susceptibility gene variants with metabolic syndrome in women. Obesity and metabolism. 2017;14(2):33-40. (In Russ.)]. doi: https://doi.org/10.14341/OMET2017233-40

8. Furue M, Tsuji G, Chiba T, et al. Cardiovascular and Metabolic Diseases Comorbid with Psoriasis: Beyond the Skin. Intern Med. 2017;56(13):1613-1619. doi: https://doi.org/10.2169/internalmedicine.56.8209.

9. Puig L, Kirby B, Mallbris L, et al. Psoriasis Beyond the Skin: A Review of the Literature on Cardiometabolic and Psychological Co-Morbidities of Psoriasis. Eur J Dermatol. 2014;24(3):305-311. doi: https://doi.org/10.1684/ejd.2014.2299

10. Takahashi H, lizuka H. Psoriasis and Metabolic Syndrome. J Dermatol. 2012;39(3):212-218. doi: https://doi.org/10.1111/j.1346-8138.2011.01408.x

11. Singh S, Young P, Armstrong AW. An Update on Psoriasis and Metabolic Syndrome: A Meta-Analysis of Observational Studies. PLoS One. 2017;12(7):1-13 doi: https://doi.org/10.1371/journal.pone.0181039

12. Лыкова С.Г., Моржанаева М.А., Немчанинова О.Б. и др. Псориаз у пациентов с метаболическим синдромом: клинические аспекть проблемы // Клиническая дерматология и венерология. 2020. — T. 19. — №2. - C. 214-222. [Lykova SG, Morzhanaeva MA, Nemchaninova OB, et al. Psoriasis in patients with metabolic syndrome: clinical aspects of the problem. Clinical Dermatology and Venereology. 2020;19(2):214-222. (In Russ.)]. doi: https://doi.org/10.17116/klinderma202019021214

13. Armstrong AW, Schupp C, Bebo B. Psoriasis Comorbidities: Results from the National Psoriasis Foundation Surveys 2003 to 2011. Dermatology. 2012;225:121-126. doi: https://doi.org/10.1159/000342180

14. Хисматуллина 3.Р., Аминева А.М., Курочкин Д.П., и др. Псориаз, псориатический артрит, метаболические нарушения и сердечно-сосудистые заболевания. Что общего? // Клиническая дерматология и венерология. - 2020. T. 19. — №2. - C. 139-147. [Khismatullina ZR, Amineva AM, Kurochkin DP, et al. Psoriasis, psoriatic arthritis, metabolic disorders and cardiovas- cular disease. What is common? Clinical Dermatology and Venereology. 2020;19(2):139-147. (In Russ.)]. doi: https://doi.org/10.17116/klinderma202019021139

15. Донцова Е.В. Особенности психоэмоционального состояния больных псориазом с метаболическим синдромом // Terra Medica. - 2013. - T. 72. — №2. - C. 39-41. [Dontsova EV. Psychoemotional features of psoriasis patients with metabolic syndrome. Terra Medica. 2013;72(2):39-41. (In Russ.)].

16. Донцова Е.В., Новикова Л.А. Сравнительная характеристика показателей оксидативного стресса у больных псориазом с различной степенью тяжести процесса и метаболическим синдромом // Кремлевская медичина. Клинический вестник. 2018. - №1. - C. 45-48. [Dontsova EV, Nikolaeva LA. Comparative indicators' characteristic of oxidative stress in patients with psoriasis of varying severity and metabolic syndrome. Kremlevskaya medicina. Klinicheskii vestnik. 2018;1:45-48. (In Russ.)].

17. Takahashi $H$, linuma S, Honma M, et al. Increased Serum C-reactive Protein Level in Japanese Patients of Psoriasis with Cardio- And Cerebrovascular Disease. J Dermatol. 2014;41(11):981-985. doi: https://doi.org/ 10.1111/1346-8138.12632

18. Vadakayil AR, Dandekeri S, Kambil SM, et al. Role of C-reactive Protein as a Marker of Disease Severity and Cardiovascular Risk in Patients with Psoriasis. Indian Dermatol Online J. 2015;6(5):322-325. doi: https://doi.org/10.4103/2229-5178.164483
19. Borska L, Kremlacek J, Andrys C, et al. Systemic Inflammation, Oxidative Damage to Nucleic Acids, and Metabolic Syndrome in the Pathogenesis of Psoriasis. Int J Mol Sci. 2017;18(11):2238. doi: https://doi.org/10.3390/ijms18112238

20. Павлова Т.Г., Матусевич С.Л., Шибанова Н.Ю. Анализ влияния антропометрических показателей на особенности клинического течения псориаза // Медицинская наука и образование Урала. 2013. — T. 73. — №1. — C. 46-48. [Pavlova TG, Matusevich SL, Shibanova NY. Antropometric parametres influence on psoriasis clinical traits. Medical science and education of Ural. 2013;73(1):46-48. (In Russ.)].

21. Лыкова С.Г., Немчанинова О.Б., Павлова Т.Г., и др. Особенности методического подхода при разработке лечебнопрофилактических мероприятий по оптимизации питания и отдельных составляющих образа жизни больных псориазом // Клиническая дерматология и венерология. - 2018. - Т. 17. №2. - C. 108-113. [Lykova SG, Nemchaninova OB, Pavlova TG, et al. Special considerations of methodical approach in the development of therapeutic and preventive measures to optimize the diet and some aspects of the lifestyle of patients with psoriasis. Clinical Dermatology and Venereology 2018;17(2):108-113. (In Russ.)]. doi: https://doi.org/10.17116/klinderma2018172108-113.

22. Немчанинова О.Б., Павлова Т.Г., Позднякова О.Н., и др. Влияние отдельных составляющих образа жизни на тяжесть клинического течения у больных псориазом на территории Кемеровской области // Медицинский альманах. - 2018. - Т. 52. - №1. C. 130-132. [Nemchaninova OB, Pavlova TG, Pozdnjakova ON, et al. The influence of individual lifestyle components on the severity of clinical course in patients with psoriasis in Kemerovo region. Medical almanac. 2018;52(1):130-132. (In Russ.)].

23. Перламутров Ю.Н., Микрюков А.В. Клинико-лабораторные характеристики псориаза, ассоциированного с гормональнометаболическими нарушениями // Российский журнал кожных и венерических болезней. — 2013. — №5. - С. 46-50. [Perlamutrov YuN, Mikryukov AV. Clinical and laboratory characteristics of psoriasis associated with hormonal metabolic disorders. Russian Journal of Skin and Venereal Diseases. 2013;5:46-50. (In Russ.)].

24. Guénard F, Houde A, Bouchard L, et al. Association of LIPA Gene Polymorphisms with Obesity-Related Metabolic Complications Among Severely Obese Patients. Obesity (Silver Spring). 2012;20(10):2075-2082. doi: https://doi.org/10.1038/oby.2012.52

25. Fall T, Ingelsson E. Genome-wide association studies of obesity and metabolic syn- drome. Mol Cell Endocrinol. 2014;382(1):740-57. doi: https://doi.org/10.1016/.mce.2012.08.018

26. Frayling TM, Timpson NJ, Weedon MN, et al. A common variant in the FTO gene is associated with body mass index and predisposes to childhood and adult obesity. Science. 2007;316(5826):889-894. doi: https://doi.org/10.1126/science.1141634

27. Gulati P, Yeo GS. The biology of FTO: from nucleic acid demethylase to amino acid sensor. Diabetologia. 2013;56(10):2113-2121. doi: https://doi.org/10.1007/s00125-013-2999-5

28. Cheung MKM, Yeo GSH. FTO biology and obesity: why do a billion of us weight $3 \mathrm{~kg}$ more? Front Endocrinol. 2011;2(4):1-9. doi: https://doi.org/10.3389/fendo.2011.00004

29. Wahlen K, Sjolin E, Hoffstedt J. The common rs9939609 gene variant of the fat mass and obesity-associated gene FTO is related to fat cell lipolysis J. Lipid Res. 2008;49(3):607-611. doi: https://doi.org/10.1194/jr.M700448-JLR200

30. Mehrdad M, Doaei S, Gholamalizadeh M, et al. Association of FTO rs9939609 polymorphism with serum leptin, insulin, adiponectin, and lipid profile in overweight adults. Adipocyte. 2020;9(1):51-56. doi: https://doi.org/10.1080/21623945.2020.1722550

31. Claussnitzer M, Simon N, Dankel SN, et al. FTO obesity variant circuitry and adipocyte browning in humans. N Engl J Med. 2015:373:895-907. doi: https://doi.org/10.1056/NEJMoa1502214

32. Legry V, Cottel D, Ferrières J, et al. Effect of an FTO polymorphism on fat mass, obesity, and type 2 diabetes mellitus in the French MONICA Study. Metabolism. 2009;58(7):971-975. doi: https://doi.org/10.1016/j.metabol.2009.02.019

33. Peng $S, Z$ Zhu Y, Xu F, et al. FTO gene polymorphisms and obesity risk: a meta-analysis. BMC Medicine. 2011;9(71):1-15. doi: https://doi.org/10.1186/1741-7015-9-71

34. Liguori R, Labruna G, Alfieri A, et al. The FTO gene polymorphism (rs9939609) is associated with metabolic syndrome in morbidly obese subjects from southern Italy. Molecular and Cellular Probes. 2014;28(4):195-199. doi: https://doi.org/10.1016/j.mcp.2014.03.004 
35. Meyre D, Delplanque J, Chèvre JC, et al. Genome-wide association study for early- onset and morbid adult obesity identifies three new risk loci in European populations. Nat Genet. 2009;41(2).157-159. doi: https://doi.org/10.1038/ng.301

36. Sandholt CH, Sparsø T, Grarup N, et al. Combined analyses of 20 common obesity susceptibility variants. Diabetes 2010;59(7):1667-1673. doi: https://doi.org/10.2337/db09-1042

37. Li $X$, Song $F$, Jiang $H$, et al. A genetic variation in the fat mass- and obesity-associated gene is associated with obesity and newly diagnosed type 2 diabetes in a Chinese population. Diabetes Metab Res Rev. 2010;26(2):128-132. doi: https://doi.org/10.1002/dmrr.1066

38. Кочетова О.В., Ахмадишина Л.З., Корытина Г.Ф., и др. Анализ роли полиморфных вариантов генов, ассоциированных с ожирением, в развитии метаболического синдрома у женщин // Ожирение и метаболизм. - 2017. - Т. 14. — №2. - С. 33-40. [Kochetova OV, Akhmadishina LZ, Korytina GF, et al. Association of obesity susceptibility gene variants with metabolic syndrome in women. Obesity and metabolism. 2017;14(2):33-40. (In Russ.)]. doi: https://doi.org/10.14341/OMET2017233-40

39. Haller S, Spiegler J, Hemmelmann C, et al. Polymorphisms in FTO and MAF Genes and Birth Weight, BMI, Ponderal Index, Weight Gain in a Large Cohort of Infants with a Birth Weight below 1500 Grams. PLoS One. 2013;8(6):e66331. doi: https://doi.org/10.1371/journal.pone.0066331

40. Speakman JR, Rance KA, Johnstone AM. Polymorphisms of the FTO Gene Are Associated with Variation in Energy Intake, but Not Energy Expenditure. Obesity (Silver Spring). 2008;16(8):1961-1965. doi: https://doi.org/10.1038/oby.2008.318

41. Castellini G, Franzago M, Bagnoli S, et al. Fat mass and obesityassociated gene (FTO) is associated to eating disorders susceptibility and moderates the expression of psychopathological traits. PLOS ONE. 2017;12(3):1-14. doi: https://doi.org/10.1371/journal.pone.0173560

42. Karra E, O'Daly OG, Choudhury Al, et al. A Link Between FTO, Ghrelin, and Impaired Brain Food-Cue Responsivity. J Clin Invest. 2013;123(8):3539-3551. doi: https://doi.org/10.1172/JCl44403

43. Danga LC, Samanez-Larkin GR, Smith CT, et al. FTO affects food cravings and interacts with age to influence age-related decline in food cravings. Physiology \& Behavior. 2018;192(1):188-193. doi: https://doi.org/10.1016/j.physbeh.2017.12.013

44. Бондарева Э.А., Задорожная Л.В., Хомякова И.А. Т/А-полиморфизм гена FTO и образ жизни ассоциированы с накоплением жира в разных возрастных группах мужчин // Ожирение и метаболизм - 2019. - T. 16. - №2 - C. 49-53. [Bondareva EA, Zadorozhnaya LV, Khomyakova IA. T/A polymorphism of the FTO gene and lifestyle are associated with fat accumulation in different age groups of men. Obesity and metabolism. 2019;16(2):49-53. (In Russ.)]. doi: https://doi.org/10.14341/omet9798

45. Zhang Q, Xia X, Fang S, Yuan X. Relationship Between Fat Mass and Obesity-Associated (FTO) Gene Polymorphisms with Obesity and Metabolic Syndrome in Ethnic Mongolians. Samuels DC, ed. Med Sci Monit. 2018;24(6):8232-8238 doi: https://doi.org/10.12659/MSM.910928

46. Rutters F, Nieuwenhuizen AG, Bouwman F, et al. Associations between a single nucleotide polymorph- ism of the FTO Gene (rs9939609) and obesity-related characteristics over time during puberty in a Dutch children cohort. J Clin Endocrinol Metab. 2011;96(6):939-942. doi: https://doi.org/10.1210/jc.2010-2413

47. Labayen I, Ruiz JR, Ortega FB, et al. Association between the FTO rs9939609 polymorphism and leptin in European adolescents: a possible link with energy balance control. The HELENA Study. Int J Obesity. 2011;35(1):66. doi: https://doi.org/10.1038/ijo.2010.219

48. Duicu C, Mărginean CO, Voidăzan S, et al. FTO rs 9939609 SNP Is Associated With Adiponectin and Leptin Levels and the Risk of Obesity in a Cohort of Romanian Children Population. Medicine (Baltimore). 2016;95(20):e3709. doi: https://doi.org/10.1097/MD.0000000000003709

49. Xi B, Shen $Y$, Zhang M, et al. The common rs9939609 variant of the fat mass and obesity-associated gene is associated with obesity risk in children and adolescents of Beijing, China. BMC Med Genet. 2010;11(1):107. doi: https://doi.org/10.1186/1471-2350-11-107

50. He D, Fu M, Miao S, et al. FTO gene variant and risk of hypertension: A meta-analysis of 57,464 hypertensive cases and 41,256 controls. Metabolism. 2014;63(5):633-639. doi: https://doi.org/10.1016/j.metabol.2014.02.008

51. Coto-Segura P, González-Lara L, Eiris N, et al. Effect of the FTO rs9930506 polymorphism on obesity and the main clinical outcomes in patients with psoriasis. British Journal of Dermatology. 2014;171(4):917-919. doi: https://doi.org/10.1111/bjd.13000

52. Tupikowska-Marzec M, Kolačkov K, Zdrojowy-Wełna A, et al. The Influence of FTO Polymorphism rs9939609 on Obesity, Some Clinical Features, and Disturbance of Carbohydrate Metabolism in Patients with Psoriasis. Biomed Res Int. 2019;2019:1-5. doi: https://doi.org/10.1155/2019/7304345

\section{ИНФОРМАЦИЯ ОБ АВТОРАХ [AUTHORS INFO]:}

* Мыльникова Екатерина Сергеевна, ординатор [Ekaterina S. Mylnikova, resident]; адрес: Россия, 620028, г. Екатеринбург, ул. Репина, д. 3 [address: 3 Repina street, 620028, Yekaterinburg, Russia]; ORCID: https://orcid.org/0000-0001-8620-4044; eLibrary SPIN: 5101-0075; e-mail: shadael96@mail.ru

Уфимцева Марина Анатольевна, д.м.н., профессор [Marina A. Ufimtseva, MD, PhD, Professor]; ORCID: https://orcid.org/0000-0002-4335-9334; eLibrary SPIN: 4753-7210; e-mail: mail-m@mail.ru Попов Артем Анатольевич, д.м.н., доцент [Artem A. Popov, MD, PhD]; ORCID: https://orcid.org/0000-0001-6216-2468; eLibrary SPIN: 5083-9389; e-mail: art_popov@mail.ru

Федотова Лариса Валентиновна, к.м.н. [Larisa V. Fedotova, MD, PhD]; ORCID: https://orcid.org/0000-0001-7173-7091; eLibrary SPIN: 5548-7201; e-mail: medlight65@mail.ru

Бочкарев Юрий Михайлович, к.м.н., доцент [Yuri M. Bochkarev, MD, PhD]; ORCID: https://orcid.org/0000-0001-6298-7216; eLibrary SPIN: 3830-2810; e-mail: bochkarev.ju.m@gmail.com

Жунисова Динара Сакеновна, аспирант [Dinara S. Zhunisova, postgraduate student];

ORCID: https://orcid.org/0000-0002-9265-4751; eLibrary SPIN: 2234-5757; e-mail: dinara2690dvk@mail.ru

\section{ЦИТИРОВАТЬ:}

Уфимцева М.А., Попов А.А., Федотова Л.В., Мыльникова Е.С., Бочкарев Ю.М., Жунисова Д.С. Псориаз и метаболический синдром: обзор литературы // Ожирение и метаболизм. - 2020. — Т. 17.— №4. — С. 369-374. doi: https://doi.org/10.14341/omet12517

\section{TO CITE THIS ARTICLE:}

Ufimtseva MA, Popov AA, Fedotova LV, Mylnikova ES, Bochkarev YM, Zhunisova DS. Psoriasis and metabolic syndrome: a review. Obesity and metabolism. 2020;17(4):369-374. doi: https://doi.org/10.14341/omet12517 